\title{
Surdez e educação: escolas inclusivas e/ou bilíngues?
}

\author{
Sylvia da Silveira Nunes \\ Universidade Federal de Itajubá - Itajubá - MG \\ Ana Lúcia Saia \\ Universidade Federal de Itajubá - Itajubá - MG \\ Larissa Jorge Silva \\ Universidade Federal de Itajubá - Itajubá - MG \\ Soraya D’Angelo Mimessi \\ Universidade Federal de Itajubá - Itajubá - MG
}

\section{Resumo}

O objetivo do presente texto é debater as questões que envolvem a escolarização do sujeito surdo, contribuindo para as propostas sobre a educação do surdo. Para tal, partimos da concepção de surdez como a experiência subjetivante da perda auditiva. Por meio da discussão de duas propostas educacionais (clínico-terapêutica e socioantropológica) buscamos localizar a reflexão para além da patologia em busca de uma escolarização que permita ao surdo a experiência formativa que a escola deve oferecer a todos. Nesse sentido, a educação inclusiva e a escola bilíngue para surdos são discutidas. Concluímos que políticas públicas que valorizem a Língua Brasileira de Sinais (Libras) tanto nos espaços escolares como nos demais espaços sociais seriam um caminho para que o aluno surdo não tivesse acesso a Libras apenas na escola.

Palavras-chave: Surdo; educação especial; Língua Brasileira de Sinais.

\section{Deafness and education: school inclusion and/or bilingual?}

\begin{abstract}
The objective of this paper is to discuss the issues surrounding the education of the deaf subject, contributing to the proposals on deaf education. To do this, we start from the concept of deafness as the subjective experience of hearing loss. Through the discussion of two educational proposals (clinical-therapeutic and socio-anthropological) seek to locate the reflection beyond the pathology in search of an education that allows the deaf to formative experience that the school should offer everyone. In this sense, inclusive education and bilingual school for the deaf are discussed. We conclude that public policies that value the Brazilian Sign Language (Libras) both in school and in other social spaces would be a way for deaf students had no access to Libras only at school.
\end{abstract}

Keywords: Deaf; especial education; Brazilian Sign Language.

\section{¿Sordera y educación: escuelas inclusivas y/o bilingües?}

\section{Resumen}

El objetivo del presente texto es debatir las cuestiones que involucran la escolarización del sujeto sordo, contribuyendo para las propuestas sobre la educación del sordo. Para tal, se partió de la concepción de sordera como la experiencia resultante de la pérdida auditiva. Por medio de la discusión de dos propuestas educacionales (clínico-terapéutica y socio antropológico) se buscó localizar la reflexión para más allá de la patología en búsqueda de una escolarización que permita al sordo la experiencia formativa que la escuela debe ofrecer a todos. En ese sentido, la educación inclusiva y la escuela bilingüe para sordos son discutidas. Se concluye que políticas públicas que valor en la Lengua Brasileña de Señales (Libras) tanto en los espacios escolares como en los demás espacios sociales serían un camino para que el alumno sordo no tuviese acceso a Libras sólo en la escuela.

Palabras clave: Sordo; educación especial; Lengua Brasileña de Señales. 


\section{Introdução}

A educação do surdo apresentou diferentes concepções ao longo da história. Da oralização ortodoxa que buscava impedir qualquer gesto ou sinal à defesa da língua de sinais como natural do surdo, diversas propostas práticas fizeram e fazem parte do cotidiano dos surdos nas escolas e nas instituições especializadas. O objeto de estudo do presente artigo é debater a polêmica educação do surdo. Para tanto, julgamos necessário explicitar a concepção de surdez que utilizamos, para avançar, ainda que brevemente, nas propostas educacionais para surdez, contribuindo para se pensar nos limites e alcances da educação inclusiva para alunos surdos, bem como na possibilidade da educação bilíngue.

\section{Pensando a surdez}

A surdez é uma alteração no sistema auditivo e/ou nas vias auditivas que reduz ou impede o acesso aos estímulos sonoros. Tal alteração dependerá da localização da perda (ouvido médio, interno, unilateral, bilateral etc.); do momento da perda (antes ou depois da aquisição da linguagem, o que recebe o nome de surdez pré ou pós-liguística); e da intensidade da perda (leve, moderada, severa ou profunda).

Assim, sob o título de "surdo", podemos abordar casos completamente distantes, tais como: uma criança que nasce com surdez profunda, nos dois ouvidos, filha de pais surdos, participantes de comunidades surdas em que a Língua Brasileira de Sinais (Libras) é cotidianamente falada e de classe média de uma grande cidade. E outro como o caso de um jovem, de classe baixa e da zona rural, com uma perda leve, após um acidente na adolescência, sem convívio com a Libras. O nosso jovem já era falante da língua portuguesa quando adquiriu a surdez, mas a nossa criança hipotética nasceu surda e, por isso, a sua vivência da surdez é diferenciada do rapaz, uma vez que está em questão qual língua ela irá aprender primeiro e onde se dará esse aprendizado. Trata-se de um debate que nós profissionais da área de saúde e educação não podemos negligenciar.

O jovem em questão pode ser chamado de deficiente auditivo (Bittencourt, \& Montagnoli, 2007; Castilho Lopes, 2011; Feneis, 1999), se fizer uso de informações sonoras, por meio de instrumentos (aparelhos auditivos, implante coclear etc.). Os próprios envolvidos se dividem na forma de tratamento, que pode ser: deficientes auditivos, surdos ou Surdos.

Mas, para além dessa divisão, a definição de surdez que utilizamos até agora ainda não é suficiente para inserirmos nosso objeto de estudo na discussão da educação bilíngue $^{1}$ e/ou inclusiva por dois motivos: pela diversidade cultural englobada na definição de surdez e pelo dilema de

1 Por educação bilíngue estamos nos referindo à escola de educação básica para alunos surdos, em que duas línguas são trabalhadas: a Libras e a Língua Portuguesa, sobretudo, na sua modalidade escrita. Essa proposta pedagógica será discutida posteriormente. pensar a surdez como deficiência ou não, o que permitirá discutir a inserção do surdo na educação inclusiva.

Primeiramente, mesmo que delimitemos como surdos apenas aqueles que têm perda auditiva bilateral, profunda, nos primeiros anos de vida, ou seja, anterior a aquisição de uma língua, ainda assim temos uma variedade muito grande de pessoas sob o título de "surdo". Nesse ponto, gostaríamos de lembrar de autores como Goffman (1963/2008) e Gilberto Velho (1979a,1979b) que estudam a diferença pelos conceitos de estigma e desvio, respectivamente. Ambos os autores nos mostram que a concepção de diferença é problemática justamente por enfatizar apenas uma característica, anulando ou minimizando todas as outras características do sujeito em questão. No caso dos surdos: a classe social, idade, religião, cor/raça, origem podem trazer muito mais informações sobre a identidade desse sujeito do que apenas a surdez. Assim, a utilização de termos como cultura surda ou comunidade surda merece cuidado não pela falta de legitimidade de produção cultural e de laços sociais que esses grupos podem construir, mas pela delimitação de que esses espaços não são os únicos de produção de laços sociais e significados para sujeitos que têm na marca de sua subjetividade a surdez, dentre muitas outras características.

Com isso, queremos dizer que qualquer frase do tipo "todo surdo é...", assim como qualquer definição de outras minorias (em termos de poder e não quantidade populacional) carrega em si mesma uma violência por administrar um rótulo que amarra o sujeito. É assim que muitas vezes acreditamos que os cegos são músicos natos, que os surdos são agitados, que as pessoas com paralisia cerebral não são inteligentes, que os homossexuais são promíscuos etc. Enfim, cuidamos para deixar claro que as reflexões sobre a surdez e o sujeito surdo presentes neste texto têm a limitação de toda generalização. Nosso objetivo é dialogar com autores, perspectivas e experiências de pesquisa envolvendo a escolarização dos sujeitos surdos, sem com isso estabelecer verdades sobre o tema, mas ao contrário, contribuir para o debate polêmico da educação do surdo e ainda pensar sobre políticas públicas que alcancem os direitos dos surdos a uma escolarização de qualidade.

Vale lembrar também que, sendo os surdos uma minoria estigmatizada, faz-se necessária uma reflexão acerca do trato social para com minorias. Para Goffman (2008), os indivíduos estigmatizados, como as pessoas com deficiência, o são devido a uma linguagem de relações e não de atributos. Considerando tais categorias como advindas de relações, torna-se possível sua reconstrução.

A atribuição unicamente ao próprio indivíduo por seu estágio de exclusão/inclusão, desresponsabiliza a sociedade como um todo dos processos de criação e reprodução dessa lógica perversa, que, no máximo, permite aos excluídos a possibilidade de uma adaptação junto aos modelos históricos, econômicos e culturais predominantes - ditos como "normais". Utilizam-se de muitos eufemismos para com o excluído, tornando sua presença tolerável, à medida que se molde aos outros sem lhes trazer "prejuízos" pessoais e financeiros, isto é, sem necessidade de mudanças em 
prol do outro. Por outro lado, a educação inclusiva caminha para o oposto disso ao propor mudanças estruturais em prol da real inserção de todos os alunos, independentemente das diversidades.

Nesse sentido, Luz (2013) afirma que a aparição do indivíduo, quando é impedida como a falta de acesso a um idioma, torna-se uma potência não realizada, um corpo biológico. É uma forma de esquecer alguém que está à nossa frente, que pode ser atuante e responsável por também renovar o mundo.

O segundo ponto a ser aclarado é a delimitação da surdez como deficiência ou não. Do ponto de vista dos militantes surdos (Feneis, 1999; Campello, \& cols, 2012), há uma reivindicação expressa de que o surdo não seja tratado como deficiente. É que dadas as condições adequadas para o aprendizado da Libras e da comunicação por meio dela, os surdos, segundo os militantes, não se sentem deficientes. Neste sentido, é visto que o indivíduo surdo não pressupõe uma identidade única revelada em traços comuns e universais. Ao contrário, os surdos participam de uma identidade, dinâmica, mutável, colocando a perspectiva política e as relações de poder como pontos fundamentais de condicionamento e direção do olhar sobre o surdo.Sem essa percepção, a sociedade e, consequentemente, a escola continuam a reproduzir um contexto social e escolar a partir do olhar do ouvinte (Skliar, 2013).

As Línguas de Sinais foram ganhando o estatuto de língua a partir dos estudos estadunidenses da década de 1960 (Skliar, \& Massone, 1995; Lacerda, 1998; Bisol, Simioni, \& Sperb, 2008). No Brasil, foi em 2002, por meio da Lei n 10.436 (Brasil, 2002), regulamentada pelo Decreto 5.626 de Dezembro de 2005 (Brasil, 2005), que a Libras foi reconhecida como a primeira língua dos surdos, sendo a Língua Portuguesa na modalidade escrita a segunda língua.

Apesar da regulamentação formal no que se refere ao direito à comunicação dos surdos no país através da Libras, ainda constata-se que estes encontram entraves para exercerem tal direito nos diversos segmentos da vida social, sendo privados no acesso à educação, cultura, lazer, informação etc. Por exemplo, quanto à política de educação, frequentemente as escolas regulares colocam como requisito de escolarização dos alunos surdos o enquadramento aos padrões ditos "normais", desrespeitando o desenvolvimento das singularidades destes. Ou seja, valorizam-se, exclusivamente, a oralização e a leitura labial, em detrimento da comunicação, não apenas em sala de aula, pela Libras.

Também em 2002, o Ministério da Educação (MEC) lançou o Programa Nacional de Educação de Surdos com o objetivo de promover cursos de formação de professores/ instrutores surdos para ministrarem cursos de LIBRAS, de formação de tradutores/intérpretes de LIBRAS, e de formação de professores de Língua Portuguesa para surdos.

Com isso foi criado pelo MEC, desde 2002, um Centro de Capacitação de Profissionais da Educação e de Atendimento às pessoas com Surdez (CAS), objetivando socializar informações sobre educação de surdos e execução de cursos propostos para os profissionais. O Estado passou a adotar para a educação dos surdos a proposta bilíngue, a qual busca possibilitar que as crianças surdas se desenvolvam por meio da língua de sinais e, posteriormente, também aprendam o português, podendo usar a modalidade oral-auditiva e/ou escrita. A Libras passou a ser considerada a primeira língua dos surdos e o português a segunda. Assim, esses avanços tanto no campo científico como normativo e jurídico nos mostram que o surdo é capaz de ter acesso a qualquer conhecimento por meio da Libras.

No entanto, voltamos a nossa pergunta: a surdez é ou não é uma deficiência? Para Bueno (1998), a surdez não é uma doença, mas uma condição intrinsecamente adversa. Se assim não fosse, as doenças que ocasionaram a surdez não seriam combatidas. Existe a perda auditiva. Por outro lado, o autor não se identifica com as posturas normalizadoras que querem transformar o surdo em ouvinte "com limitações".

Historicamente ${ }^{2}$, sabemos que os surdos, na maior parte do tempo, foram tratados de forma preconceituosa, discriminatória e segregadora. Nesse caminhar histórico, muitas propostas pedagógicas partiam do pressuposto de que o surdo precisava se transformar o máximo possível para se parecer com o ouvinte. Pensando a história como um movimento de continuidade e descontinuidade como nos ensina Hobsbawm (1995), questionamos o quanto, ainda hoje, o preconceito contra o surdo se relaciona com o uso da Libras como meio principal de comunicação e apreensão do mundo.

Para Slomski (2012), não é a surdez contida em si mesma que detém toda a gravidade. As limitações e as consequências secundárias como a mudez e a dificuldade de aquisição da linguagem exercem fatores negativos para o surdo. Assim, infere-se que a problemática maior se encontra no meio social, que não proporciona ao surdo a aquisição de uma língua.

Concluímos que a dissociação da surdez com a deficiência revela a condição bilíngue da surdez, isto é, da possibilidade e importância de o surdo ter acesso a Libras como língua primeira e estruturante de sua identidade e, a partir dela, ter acesso a todas as informações do mundo como qualquer pessoa. Não é necessário o olhar penalizado tampouco a crença na incapacidade do surdo. Porém, como estamos falando de uma minoria e toda a discussão sempre lembrará as relações de poder que estruturam o mundo em que vivemos, a negação da surdez como deficiência não retira dos surdos as garantias políticas legais já conquistadas para as pessoas com deficiência ${ }^{3}$. Ou seja, a concepção de

\footnotetext{
2 Sobre a história da educação dos surdos, ver: Monteiro (2006), Sacks (2010) e Soares (2005).

3 Na carta aberta ao Ministro da Educação escrita pelos sete primeiros surdos a se tornarem doutores na área de Letras e Linguística e que também são professores de universidades federais, escrita em junho de 2012, os autores defendem a escola bilíngue para surdos e lembram a importância de consultar as pessoas com deficiência no momento da elaboração de políticas públicas que Ihes digam respeito, disposta na Convenção Internacional sobre os Direitos das Pessoas com Deficiência (Campello,\& cols., 2012). Vale ressaltar que tal convenção é a única no ordenamento jurídico brasileiro que equivale à emenda constitucional.
} 
surdez que ultrapassa a conceituação de deficiência não visa negar o déficit orgânico, mas lançar luz para a experiência subjetiva marcada pela surdez: para as possibilidades que essa condição traz; para as trocas intersubjetivas facilitadas pelo convívio em grupos ou comunidades entre surdos; para além da comparação constante com os ouvintes e para a denúncia presente nas propostas pedagógicas "ouvintistas"4.

Nesse sentido, concordamos com Skliar (1999, p. 10) que nota a diversidade dentro do território de representações sobre surdez

A surdez configura-se atualmente como um território de representações que não pode ser facilmente delimitado ou distribuído em "modelos conceituais opostos", tais como clínicos ou sócio-antropológicos. Trata-se melhor dizendo de um território irregular por onde transitam discursos e práticas assimétricos quanto às relações de poder/saber que os determinam (grifos nossos).

É a assimetria nas relações de poder que justifica e legitima as comunidades surdas como possibilidades de reorganização de novos encontros discursivos que não sejam marcados apenas pela comparação constante com a "normalidade" e com o desvio. O convívio dos surdos entre si pode trazer trocas que influenciam na concepção sobre si mesmo e no acesso às produções culturais desse encontro: arte, teatro, reflexões, reivindicações etc.

\section{Propostas educacionais para os surdos}

A partir dessa concepção de surdez, podemos então entrar nos embates sobre a educação do surdo. A história da educação do surdo foi marcada por duas propostas opostas, desde o século XVI: oralismo x gestualismo (Bueno, 1998; Lacerda, 1998). Para os oralistas, o surdo deve aprender a falar a língua oral; já o gestualismo pressupõe que por meio dos gestos, chamados hoje de sinais, o surdo pode se desenvolver melhor.

Essa disputa acirrada foi relacionada por Skliar e Massone (1995) a dois modelos de compreensão da surdez: o modelo clínico-terapêutico e o modelo socioantropológico. A proposta clínico-terapêutica pensa a surdez de modo vinculado à patologia e ao déficit auditivo, embasando propostas de correção do déficit. Nessa concepção, o desenvolvimento e a linguagem só são possíveis por meio da língua oral.

Bisol e cols. (2008), por exemplo, ao estudarem as concepções de surdez na publicação de artigos científicos em periódicos nacionais da área de psicologia, notaram que

4 Skliar (1999) cria o termo ouvintismo para nomear as práticas autoritárias dos ouvintes em relação aos surdos, de modo a impor uma suposta normalidade. O autor denuncia, sobretudo, as práticas pedagógicas marcadas pela falta de diálogo com os surdos que levam à negação das múltiplas identidades surdas, bem como a um "amordaçamento da cultura surda" (p.8).
A associação entre a psicologia e o modelo clínicoterapêutico de surdez produz um olhar que tende a enfatizar, no contexto da surdez, o déficit orgânico. As diferenças costumam ser interpretadas como desvio. Percebe-se também uma tendência de compreender os surdos como um grupo homogêneo com desvantagens maturativas inerentes à condição da deficiência. Alguns autores afirmam que existem diferenças neurológicas causadas pela surdez que respondem pelos níveis e agilidade do raciocínio abstrato diferentes entre surdos e ouvintes (Bisol, \& cols., 2008, p.396).

Aqui, fica claro que a negação da deficiência colocada na bandeira do movimento surdo está relacionada a essa concepção de deficiência, que generaliza uma incapacidade que não faz parte da surdez. E, nesse contexto da perspectiva clínica, a surdez é limitada a classificações audiométricas (como perda auditiva leve, moderada, grave), as quais, como consequência, reproduzem a não aceitação da surdez e a perpetuação de preconceitos (Slomski,2012).

Já o modelo socioantropológico pressupõe que a surdez marca uma diferença linguística. Esta concepção foi formulada após os estudos estadunidenses sobre linguagem e língua de sinais, a partir da década de 1960, que notaram que: 1) os surdos formavam comunidades, onde se desenvolvia espontaneamente uma língua de sinais; 2) crianças surdas filhas de pais surdos tinham melhor desempenho acadêmico e não apresentavam problemas sociais e afetivos; 3) as línguas de sinais têm a mesma complexidade que a língua oral ${ }^{5}$. Assim, essa concepção nasceu como oposição ao oralismo. Seu pressuposto é de que a língua de sinais é a língua natural do surdo, o que, por consequência, melhor garantiria o desenvolvimento da criança surda (Skliar, \& Massone, 1995).

Por outro lado, ao olhar criticamente para a história da educação dos surdos, Bueno (1998) nos lembra que o oralismo, muitas vezes, é tido como "inimigo", uma vez que são nítidos o preconceito e o autoritarismo presentes no desejo de tornar o surdo o mais próximo possível do ouvinte. No entanto, é fundamental contextualizar a surdez como diferença biológica ou linguística em uma sociedade que tem de antemão espaços bastante restritivos à diferença. $A$ defesa pura e simples da educação bilíngue para o surdo não resolve a questão se, conjuntamente, não pensarmos políticas públicas que contemplem a língua de sinais nos mais diversos espaços sociais e se não admitirmos que o convívio com a diferença, no que pese não ser tranquilo, é o único caminho para a humanização. Para Skliar (2013), no que diz respeito ao ensino bilíngue é preciso consistência política que contemple e atue, discutindo a assimetria entre surdos e ouvintes representados na forma de poder e saber

5 A partir desses estudos, notou-se que a língua de sinais é tão complexa quanto qualquer outra: caracteriza-se por uma modalidade linguística espaço-visual, em que a comunicação se dá pelas expressões faciais, pelas mãos e por movimentos do corpo. As línguas de sinais são produzidas regionalmente como são as línguas orais. 
que acabam por controlar e limitar a aprendizagem. E, posto isso, paralelamente à luta pela educação do surdo,seja bilíngue ou inclusiva, é fundamental a luta contra o preconceito em relação ao surdo nos mais diversos espaços de convívio social.

Ainda que o preconceito não tenha em seu antídoto ${ }^{6}$ apenas a convivência com a vítima do preconceito (Crochík, 2006), a familiarização e convivência com a Libras e o conhecimento sobre os debates que envolvem a educação e a inserção dos surdos na escola e nos diversos espaços sociais parecem apontar um caminho nessa luta contra o preconceito. Isso posto, não apenas os cursos de magistério, licenciaturas e fonoaudiologia precisam do curso obrigatório de Libras, como prevê o decreto 5626, de 2005 (Brasil, 2005) mas também qualquer outra formação acadêmica de nível superior teria ganhos se os alunos tivessem contato com a Libras. Nesse sentido, Angelucci e Luz (2010, p. 41) nos lembram que, comumente: "(...) profissionais da saúde e da educação acabam por transmitir aos pais, mais ou menos conscientemente, a ideia de que a pessoa surda está fora da comunicação, caso não faça adesão à língua majoritária”.

Por outro lado, vale lembrar que a dinâmica do preconceito é complexa e não unilateral. O sujeito que sofre o preconceito não está imune à sua reprodução. Assim, qualquer reflexão sobre o preconceito deve levar em conta as condições materiais de sua produção, uma vez que sem refletir mais amplamente sobre o preconceito como um fenômeno psicossocial, corremos o risco de culpabilizar a vítima ou de simplificarmos situações bastante complexas. De todo modo, a educação bem como o convívio social são espaços que podem nos levar a humanização e, para tal, necessário se faz encarar os nossos preconceitos, que constantemente desumanizam e empobrecem nossas relações.

\section{Educação inclusiva e surdez}

O conceito de educação inclusiva encontra-se em um limbo. Se por um lado avançamos no que se refere ao caráter de exceção presente na educação "especial", que diz respeito a uma condição especial, extraordinária, por outro, seu uso nos mostra que ainda nos distanciamos da educação democrática, pois o foco no "incluso" dá tanta luz a ele que denuncia uma inclusão ainda pela metade.

A Declaração de Salamanca, documento elaborado na Conferência Mundial sobre Educação Especial, na cidade de Salamanca, na Espanha, em 1994, nos ajudou a expandir o conceito de necessidades educativas especiais a todo aquele que precisasse da adaptação da escola para que suas necessidades fossem atendidas e a escolarização, assim, pudesse se encaminhar. É a partir desse marco que a educação inclusiva vai se popularizando, partindo sim da educação especial, mas vislumbrando uma nova concepção

6 Horkheimer e Adorno (1986, p.165) dizem: “(...) ficou provado que as chances do antissemitismo são tão grandes nas regiões sem judeus como até mesmo em Hollywood". de educação: a escola precisa incluir não apenas os "especiais", mas todos os alunos.

Claro que o conceito de inclusão, bem como seu par oposto, exclusão, corre o risco de ser fetichizado (Martins, 1997), o que significa a referência a fenômenos sociais complexos por um reducionismo interpretativo que foca em apenas um aspecto como se fosse ele o "deus-demônio" culpado unicamente do problema social em questão e, logicamente, somente uma única saída é vislumbrada.

No caso da surdez, o oralismo pode encarnar esse deus-diabo, bem como a educação inclusiva ou a Libras. Não se trata, então, de buscar explicações simplistas para o distanciamento que ouvintes e surdos vivem uns dos outros, mas de notar que na estrutura social em que vivemos a lógica capitalista, desde sua formação, não prescinde de grupos que serão excluídos. No entanto, Martins (1997) auxilia consideravelmente o debate inclusão/exclusão ao afirmar que a exclusão não existe. O movimento do próprio capitalismo desenraiza para em seguida integrar novamente, mas de forma marginal, ou melhor dizendo, persistindo a lógica hierárquica da organização social. Os chamados processos de inclusão ainda persistem em incluir sim, mas incluir marginalmente, não permitindo as mesmas oportunidades a todos.

Vale lembrar que no caso da educação, a própria escola, historicamente, se constituiu com base na diferenciação entre os que seriam ou não "escolarizáveis" (Angelucci, \& Luz, 2010; Moysés, \& Collares, 1997). Os testes psicológicos e outros aparelhos institucionais foram utilizados para avaliar essa capacidade de escolarização, ou seja, com o objetivo de separar e segregar os "aptos" dos "não-aptos".

Assim, qualquer debate sobre educação inclusiva corre o risco de fetichização se não abarcar a reflexão sobre a política educacional mais ampla. Angelucci (2002) nos lembra que a educação inclusiva lança luz sobre os problemas da escola já existentes antes das políticas de inserção de alunos com deficiência no ensino regular. A educação inclusiva, como já foi dito, parte das questões levantadas pela deficiência, mas não se limita a elas, porque é a própria escola que precisa ser repensada como uma escola para todos, independentemente das diversidades.

As políticas públicas educacionais referentes à educação inclusiva não diferiram quanto a outras políticas públicas para a escola, pois os atores sociais mais importantes no processo estiveram fora das decisões: professores, alunos e suas famílias. Assim, é compreensível que professores tenham sentido seus saberes desconsiderados e isso é uma violência simbólica a sua experiência e dedicação à escola.

O fato de essa política educacional estar sendo vivida de modo tão pouco democrático e dialogado justifica, em parte, a "onda conservadora" de que só a instituição especializada seria capaz de dar conta dos alunos com deficiência.Nesse sentido, Angelucci e Luz (2010, p.35) concluem que independente do consenso sobre a educação do surdo se dar em escolas regulares ou bilíngües 
(...) os profissionais da Educação precisam de liberdade e condições objetivas para criar/recriar espaços e estratégias de aprendizagem, com a finalidade de proporcionar aos educandos - e a si mesmos - experiências de relações mais horizontais com o outro, esteja ele marcado pela diferença linguística, sensorial, orgânica, etária, cognitiva ou étnica.

São essas experiências mais horizontais marcadas pela possibilidade do encontro com o outro e sem objetivo de homogeneização do fenômeno educativo que norteiam a educação inclusiva aqui defendida. Essas experiências estão na contramão no momento histórico-político que vivemos, em que todo o fracasso escolar é imputado como responsabilidade individual. Não se trata de negar o incômodo que a diferença traz, mas de apostar na experiência formativa que essa concepção educacional é capaz de propiciar.

No que diz respeito aos dados estatísticos, no portal do Ministério da Educação ${ }^{7}$ constam gráficos intitulados "A Evolução da Educação Especial no Brasil”, realizados no ano de 2006 (MEC, 2006). Os referidos gráficos registraram no mesmo período que o número de matrículas na educação especial de 2005 e 2006 para deficientes auditivos passou de 19.646 para 21.439 e de surdos passou de 46.668 passou para 47.381. No ensino superior consta que os surdos compreendiam em 2003 o número de 665, em 2004 eram 974 e em 2005 passaram a $2.428^{8}$.

Mesmo com a melhora dos índices de admissão de alunos surdos no ensino em geral, a quantidade de pessoas surdas fora dos bancos escolares ainda é grande, o que demonstra a necessidade de políticas públicas para atender os surdos e suas famílias, bem como capacitar professores e demais atores escolares para esse atendimento.

\section{Educação inclusiva e/ou bilíngue para surdos}

Na já mencionada Carta escrita pelos sete primeiros surdos doutores e professores de universidades federais, os autores afirmam: "A educação inclusiva, grande parte das vezes, permite o convívio de todos os alunos entre si, mas não tem garantido o nosso aprendizado, o aprendizado dos surdos" (Campello, \& cols, 2012, s.p). E os autores seguem, no documento, defendendo uma escola que seja bilíngue para surdos. Essa escola, que era chamada de escola especial e que hoje é chamada de bilíngue, é apresentada pelos autores como não segregadora, mas como o espaço educacional possível para o surdo ter acesso ao conhecimento.

A escolarização do surdo nas escolas bilíngues para surdos, segundo o documento e a disposição legal, pode referir-se à educação infantil e ao ensino fundamental. Nesse sentido, a escola bilíngue pode apontar não para a segregação, mas para o preparo do surdo para o ensino médio,

\section{7 http://portal.mec.gov.br/seesp/arquivos/pdf/brasil.pdf}

8 No site, a diferenciação entre "deficientes auditivos" e "surdos" só foi feita para os dados da educação especial. Para o ensino superior, o MEC utiliza apenas "surdos". ensino superior e mercado de trabalho, onde o convívio com os ouvintes é imprescindível.

A escola bilíngue seria o espaço de socialização, de construção de uma identidade positivada, de acesso ao conhecimento e uma comunicação significativa para os que costumeiramente são "sem-lugar". Por outro lado, há que se pensar que o... "(...) problema que pode derivar para a pessoa surda é o sentimento de que apenas "lá", na escola, entre iguais, é que se pode existir" (Angelucci, \& Luz, 2010, p. 41). É necessário, então, que a dinâmica dentro da própria escola tenha um clima preparatório para as outras fases de ensino que se darão de modo inclusivo, bem como apostar, como já dissemos, em caminhos que desmistifiquem a surdez e a Libras e considerem a possibilidade de não apenas o surdo ter que aprender a língua portuguesa, como o ouvinte também se dispor a aprender a Libras.

A defesa do bilinguismo passa pela compreensão da língua de sinais e de sua representação para os surdos. Além de significar uma forma de comunicação que funciona como pré-requisito para outras aprendizagens como português e matemática. Assim, a língua de sinais representa a valorização do surdo, uma vez que permite que sejam ouvidos e representados.

Vale lembrar também que a atualidade do bilinguismo na educação é conflitiva. Há muitas vezes uma prática "pseudo-bilinguista" (Skliar, 1999). De qualquer forma, a educação bilíngue é vista pelo autor como um "paradigma oposicional", ou seja, o teor político que envolve a proposta bilíngue está na assunção do surdo como alguém cuja condição envolve uma diferença linguística. E é por isso que o termo "especial" não é mais usado junto à escola, pois... "(...) entre educação especial e educação bilíngue de surdos é imprescindível para que a educação bilíngue desenvolva uma certa profundidade política." (Skliar, 1999, p. 12).

$\mathrm{O}$ acesso político que o bilinguismo permite é notado, por exemplo, em relação à acessibilidade digital, porém, é importante compreender que a alfabetização em Língua Portuguesa é fundamental para a utilização de ferramentas digitais. Se a alfabetização se concretiza eficazmente pela aprendizagem posterior a Libras, então o bilinguismo é pré-requisito para qualquer aprendizado que necessite leitura e escrita (Corradi, 2011).

A utilização de ferramentas digitais pode não necessariamente pressupor o domínio da língua portuguesa. Pode-se observar isso em crianças ainda não alfabetizadas. Para o surdo, o problema é que grande parte das tecnologias e meios de comunicação, assim como o ensino oral, são criados geralmente por ouvintes e para ouvintes. No entanto, o bilinguismo pode ser um caminho de integração do surdo à escola e à sociedade por valorizar e facilitar a comunicação do indivíduo surdo.

Apontando mais uma possibilidade, Lacerda, Albres e Drago (2013) discutem a implementação da educação bilíngue para surdos por dois caminhos, estudando especificamente a legislação do município de São Paulo, que envolve escolas municipais de educação bilíngue para surdos e escolas regulares que recebem surdos e ouvintes, isto é, 
escolas inclusivas. As autoras concluem que a proposta da secretaria municipal de São Paulo contribui para uma educação "plural". Nas palavras das autoras: "Os documentos analisados indicam que a escolha de uma educação plural, entendendo que pessoas com surdez têm diversas necessidades e condições, e que a inclusão social desses sujeitos, no que tange à educação, pode dar-se com diferentes roupagens". (Lacerda, \& cols., 2013, p. 78).

Enfim, a partir das reflexões aqui compartilhadas, concluímos que não há consenso sobre a prática cotidiana da educação do surdo: escola bilíngue, ambiente inclusivo ou propostas que mesclem essas possibilidades. Mas de qualquer forma, estaremos dentro dos parâmetros da educação inclusiva quando não limitarmos o surdo à patologia, mas buscarmos espaços educacionais em que a Libras possa transitar como a língua oficial dos surdos e constituinte de sua subjetividade.

Além disso, romper com a questão assistencialista da educação inclusiva é algo também demorado a ser conquistado, pois a integração está estabelecida, mas o acesso ao saber ainda não se consolidou, e a aquisição da língua e do saber escolar tem dificuldades de ser legitimada. Trata-se de pensar no ensino como um direito do aluno e não apenas em uma integração baseada na instrumentalização e socialização do surdo como uma prática clínica, mas que interceda buscando a valorização da Libras e preparando os surdos da mesma forma que os demais alunos.

Dessa forma, é preciso entender que a Libras para se estabelecer como primeira língua depende de políticas públicas que desenvolvam um trabalho que tenha a intenção de atingir o centro do problema: dar mais espaço para o surdo e para a utilização da Libras.

\section{À guisa de conclusão}

Apesar do reconhecimento da Libras como língua oficial dos surdos, ainda vivemos um momento em que o seu aprendizado só ocorre quando aluno surdo ingressa na escola. Esse fato é um dado a mais nas controvérsias sobre como deve ser a educação do surdo.

Qual seria a melhor escola para o surdo? A escola bilíngue para surdos? A escola inclusiva com o convívio entre surdos e ouvintes? Uma escola que mescle as duas possibilidades, com uma sala apenas para surdos? Uma escola bilíngue para surdos apenas durante a educação infantil e o ensino fundamental?

O Estado indica atualmente o caminho do bilinguismo, mas a prática demonstra que faltam estrutura e recursos disponíveis. É na busca de políticas públicas que capacitem profissionais que atendem o surdo e sua família que fazemos a nossa aposta. Assim, a Libras não precisaria ser vivida apenas no espaço escolar e o sujeito surdo teria o direito de se comunicar em diferentes espaços sociais, tanto quanto os ouvintes o têm. Novos estudos e pesquisas podem apontar quais políticas e propostas seriam mais adequadas para se pensar na educação do surdo, com o respeito as suas particularidades e superando o chamado "ouvintismo".

Os profissionais da área de saúde, por exemplo, bem como os aparelhos de promoção de saúde - seja em nível primário, secundário ou terciário, isto é, postos de saúde, centros de saúde, centros de referências, policlínicas, hospitais etc. - são justamente espaços em que a Libras pode estar mais presente, o que levaria os pais a se familiarizarem com ela, desde o contato inicial com a surdez, seja congênita ou adquirida.

Outros espaços sociais também podem ter mais intérpretes de Libras e, assim, maior possibilidade de acesso dos surdos às informações: eventos sociais, diversos espaços religiosos, todas as programações televisivas, sítios da internet e demais ferramentas midiáticas de comunicação etc.

Todo esse convívio mais intenso com a Libras poderia tornar as experiências e as opiniões dos surdos mais próximas do universo dos ouvintes. É claro que o encontro entre ambos os grupos não precisa ser romantizado como ideal. Os conflitos fazem parte de qualquer relação humana, mas trata-se de pensar coletivamente em caminhos que não menosprezem as restrições sociais que os surdos vivem cotidianamente, bem como a desumanização que surdos e ouvintes vivem por estarem privados do convívio e aprendizado mútuo.

\section{Referências}

Angelucci, C. B. (2002). Uma inclusão nada especial: apropriações da política de inclusão de pessoas com necessidades especiais na rede pública de educação fundamental do Estado de São Paulo. Dissertação de Mestrado do Instituto de Psicologia da Universidade de São Paulo, São Paulo - SP.

Angelucci, C. B., \& Luz, R. D. (2010).Contribuições da escola para a (de)formação dos sujeitos surdos. Psicologia Escolar e Educacional,14(1), 35-44.

Bisol, C. A., Simioni, J., \& Sperb, T. (2008) Contribuições da psicologia brasileira para o estudo da surdez. Psicologia: Reflexão e Crítica, 21(3), 393-400.

Bittencourt, Z. Z. L. \& Montagnoli, A. P. (2007) Representações sociais da Surdez. Revista Medicina, 40(2), 243-9.

Bueno, J. G. S. (1998). Surdez, linguagem e cultura. Cadernos Cedes, 19(46), 41-56.

Brasil. Lei n.10.436, de 24 de abril de 2002 (2002) Dispõe sobre a Língua Brasileira de Sinais - Libras e dá outras providências. Diário Oficial da União, Brasília.

Brasil. Decreto de Lei n. 5.626, de 22 de dezembro de 2005 (2005) Regulamenta a Lei $n^{0} 10.436$, de 24 de abril de 2002, que dispõe sobre a Língua Brasileira de Sinais - Libras, e o art. 18 da Lei $n$. 10.098, de 19 de dez. 2000. Diário Oficial da União, Brasília. 
Campello, A. R., Perlín, G., Strobel, K., Stumpf, M., Rezende, P., Marque, S. R., Miranda, W. (2012). Carta aberta ao ministro da educação elaborada pelos sete primeiros doutores surdos brasileiros, que atuam nas áreas de educação e linguística. Recuperado:8 jun. 2012. Disponível: http://marianahora.blogspot. com.br/2012/06/carta-aberta-dos-doutores-surdos.html.

Castilho Lopes, M. A. (2011). Concepções de surdez de adultos surdos que utilizam língua de sinais. Dissertação de Mestrado em Psicologia, Desenvolvimento e Aprendizagem, Universidade Estadual Paulista, Bauru - SP.

Corradi, J. A. M. (2011). Acessibilidade em ambientes informacionais digitais: uma questão de diferença. São Paulo: Edunesp.

Crochík, J. L. (2006). Preconceito: indivíduo e cultura. São Paulo: Casa do Psicólogo.

Federação Nacional de Educação e Integração dos Surdos [Feneis] (1999). A educação que nós surdos queremos. Documento elaborado no Pré-Congresso ao V Congresso Latino Americano de Educação Bilíngue para Surdos. Porto Alegre, Rio Grande do Sul.

Goffman, E. (2008). Estigma: notas sobre a manipulação da identidade deteriorada. Rio de Janeiro, LTC. (Trabalho original publicado em 1963).

Hobsbawm, E. (1995) A era dos extremos - o breve século XX: 19141991(M. Santarrita, Trad.). São Paulo: Companhia das Letras.

Horkheimer, M., \& Adorno, T. W. (1986). Dialética do esclarecimento. Rio de Janeiro: Jorge Zahar.

Lacerda, C. B. F. (1998) Um pouco da história das diferentes abordagens na educação dos surdos. Cadernos Cedes, 19(46), 68-80.

Lacerda, C. B. F., Albres, N. A., \& Drago, S. L. S. (2013) Política para uma educação bilíngue e inclusiva a alunos surdos no município de São Paulo. Educação e Pesquisa, 39(1), 65-80.

Luz, R. D. (2013). Cenas Surdas: os surdos terão lugar no coração do mundo?. São Paulo: Parábola.

Martins, J. S. (1997). Exclusão social e a nova desigualdade. São Paulo: Paulus.
Ministério da Educação [MEC] (2006). A Evolução da Educação Especial no Brasil. Disponível: http://portal.mec.gov.br/seesp/ arquivos/pdf/brasil.pdf.

Monteiro, M. S. (2006). História dos movimentos dos surdos e o reconhecimento da Libras no Brasil. Revista Educação e Temática Digital, 7(2), 292-302.

Moysés, M. A. A., \& Collares, C. A. L. (1997). Inteligência abstraída, crianças silenciadas: as avaliações de inteligência. Psicologia USP, 8(1), 63-89.

Sacks, O. (2010) Vendo vozes: uma viagem ao mundo dos surdos. Tradução Laura Teixeira Motta. São Paulo: Companhia das Letras.

Soares, M. A. L. (2005). A Educação do Surdo no Brasil. Campinas, SP: Autores Associados.

Skliar, C., Massone, M. I., \& Veinberg, S. (1995) El acceso de los niños sordos al bilingüismo y al biculturalismo. Infancia y Aprendizaje, 2(69), 85-100.

Skliar, C. (1999) A localização política da educação bilíngue para surdos. Em C. Skliar (Org.),Atualidade da educação bilíngue para surdos: processos e projetos pedagógicos. Porto Alegre: Mediação.

Skliar, C. (2013). A localização política da educação bilíngue para surdos. Em C. Skliar (Org.), Atualidade da Educação Bilíngue para Surdos: Interfaces entre Pedagogia e Linguística (Vol.1, 4ª ed., pp. 7-14). Porto Alegre, RS: Mediação.

Slomski, V. G. (2012) Educação Bilíngue para surdos: concepções e implicações práticas $\left(2^{\mathrm{a}}\right.$ ed.). Curitiba: Juruá.

Velho, G. (1979a) O estudo do comportamento desviante: a contribuição da antropologia social. Em G. Velho (Org), Desvio e divergência: uma crítica da patologia social. Rio de Janeiro: Zahar Editores.

Velho, G. (1979b) Estigma e comportamento desviante em Copacabana. In: ___ (Org). Desvio e divergência: uma crítica da patologia social. Rio de Janeiro: Zahar Editores. 


\section{Sobre as autoras}

Sylvia da Silveira Nunes (sylviasnunes@yahoo.com.br; sylvia.nunes@unifal-mg.edu.br)

Doutora em Psicologia Escolar e do Desenvolvimento Humano pela Universidade de São Paulo (USP) e Docente da Universidade Federal de Alfenas (UNIFAL) e do Programa de Pós-Graduação em Desenvolvimento, Tecnologia e Sociedade da Universidade Federal de Itajubá (UNIFEI).

Ana Lúcia Saia (anasaia@projesom.com.br)

Especialista em Gestão de Pessoas e Projetos Sociais pela UNIFEI e mestre em Desenvolvimento, Tecnologia e Sociedade pela UNIFEI.

Larissa Jorge Silva (amielarissa@gmail.com)

Assistente social pela Universidade Federal de Juiz de Fora (UFJF) e mestranda do Programa de Pós-Graduação em Desenvolvimento, Tecnologia e Sociedade pela UNIFEI.

Soraya D’Angelo Mimessi (somimessi@yahoo.com.br)

Especialista em Educação pela Universidade de Taubaté (UNITAU) e mestre em Desenvolvimento, Tecnologia e Sociedade pela UNIFEI.

Agradecemos à Coordenação de Aperfeiçoamento de Pessoal de Nível Superior (Capes) pela bolsa de mestrado à Ana Lúcia Saia. 
